\title{
RNAi for Plant Improvement and Protection
}

Editors:

\section{Bruno Mezzetti}

Professor Plant Breeding and Biotechnology, Department of Agricultural, Food and Environmental Sciences - Università Politecnica delle Marche, Italy

\section{Jeremy Sweet}

Director, Sweet Environmental Consultants, Willingham, Cambridge, UK

\section{Lorenzo Burgos}

Profesor de Investigación at CEBAS-CSIC. Head of Fruit Biotechnology Group, Department of Fruit Breeding, Campus Universitario de Espinardo, Murcia, Spain 


\section{CABI is a trading name of CAB International}

CABI

Nosworthy Way

Wallingford

Oxfordshire OX10 8DE

UK

Tel: $+44(0) 1491832111$

Fax: +44(0)1491833508

E-mail: info@cabi.org

Website: www.cabi.org
CABI

745 Atlantic Avenue

8th Floor

Boston, MA 02111

USA

$\mathrm{T}:+1$ (617)682-9015

E-mail: cabi-nao@cabi.org

\section{(c) (i) $९$ BY NO NO}

(C) 2021 by CAB International. RNAi for Plant Improvement and Protection is licensed under a Creative Commons Attribution-NonCommercial-NoDerivatives 4.0 International License.

A catalogue record for this book is available from the British Library, London, UK.

References to Internet websites (URLs) were accurate at the time of writing.

ISBN-13: 9781789248890 (hardback)

9781789248806 (epdf)

9781789248913 (epub)

DOI: $10.1079 / 9781789248890.0000$

Commissioning Editor: David Hemming

Editorial Assistant: Lauren Davies

Production Editor: James Bishop

Typeset by Exeter Premedia Services Pvt Ltd, Chennai, India

Printed and bound in the UK by Severn, Gloucester 


\title{
Food and Feed Safety Assessment of RNAi Plants and Products
}

\author{
Hanspeter Naegeli ${ }^{1 *}$, Gijs Kleter ${ }^{2}$ and Antje Dietz-Pfeilstetter ${ }^{3}$ \\ ${ }^{1}$ University of Zürich, Institute of Veterinary Pharmacology and Toxicology, Zürich, \\ Switzerland; ${ }^{2}$ RIKILT Wageningen University \& Research, Wageningen, The \\ Netherlands; ${ }^{3}$ Julius Kühn-Institut, Institute for Biosafety in Plant Biotechnology, \\ Braunschweig, Germany
}

\subsection{Introduction: Steps in the Risk Assessment}

The risk assessment of genetically modified (GM) plants for food and feed use is based on a comparative approach (EFSA GMO Panel, 2011) where the composition as well as phenotypic and agronomic characteristics of the GM plant are compared with those of a conventional counterpart with a close genetic background and to additional non-GM comparator lines, which are assumed to have a history of safe use. Comparative risk assessment identifies effects intended by the genetic modification as well as possible unintended effects arising from transgene insertion into functional genome regions or from inadvertent impacts of the transgene product(s) on plant metabolic pathways. If differences and/or lack of equivalence between the GM plant and its comparator(s) above natural variation are identified, possible adverse effects on human and animal health have to be considered.

This type of hazard identification is the first step in the risk assessment of a GM plant. Intended and unintended differences in contrast to comparator(s) are then evaluated with respect to adverse health effects. This involves in the first place toxicological and allergenicity assessment of newly expressed proteins (NEPs). In the case of RNA interference (RNAi) plants not expressing any new protein, these assessments are inapplicable. Instead, as the introduction of a gene silencing construct may cause silencing of 'off-target' genes, bioinformatics searches for 'off-target' sequences in the plant genome should be part of hazard characterization. If plant metabolic genes are silenced, unintended interferences with endogenous metabolic pathways are also possible and may cause alterations in metabolites and precursors of suppressed metabolic routes, justifying - on a case-by-case basis - analysis of specific RNAs or metabolites (EC, 2013).

An important aspect of risk assessment is the determination of exposure to the food and feed derived from GM plants, which involves identification of the population groups and animal species exposed as well as the extent of exposure. A starting point for the extent of exposure is the expression product of the introduced genetic modification, which is double-stranded RNA (dsRNA) in the case of RNAi plants. Its level, as well as levels of constituents altered as a result of the genetic modification, should be

*Corresponding author: hanspeter.naegeli@vetpharm.uzh.ch 
determined in plant parts used for food or feed. For estimating exposure from dietary intake or feed consumption, the stability of the dsRNA and derived small interfering RNAs (siRNAs) during storage and processing of plant material as well as during oral consumption need to be taken into account.

The final risk characterization of food and feed derived from GM RNAi plants is based on the results from the evaluation of potential adverse effects on human and animal health and from exposure assessment.

\subsection{Potential Hazards of Food and Feed Derived from RNAi Plants}

\subsubsection{Adverse changes of plant metabolism}

The principle of RNAi is used to modulate agricultural, phenotypic or compositional characteristics of plants by promoting gene silencing (Fire et al., 1998; Dykxhoorn et al., 2003; Frizzi and Huang, 2010). This strategy does not pose an inherent hazard to consumers or the environment, because it exploits gene regulation mechanisms that occur naturally in plants and animals. There are already manifold examples of spontaneously occurring RNAi-mediated genetic traits that were selected by conventional plant breeding. Such 'natural' gene silencing traits involve, for example, changes in the coat color of soybean seed (Tuteja et al., 2004) and maize stalk (Della Vedova et al., 2005), or mediate a low glutelin level in rice (Kusaba et al., 2003). So far, the RNAi strategy has been adopted in biotechnology-derived food crops to generate virus-resistant varieties (Sherman et al., 2015), optimize their agronomic performance (Ogita et al., 2003), provide pest and pathogen protection (Baum et al., 2007; Gordon and Waterhouse, 2007; Mao et al., 2007; Koch and Kogel, 2014), facilitate industrial processes like starch production (EFSA GMO Panel, 2006), improve the nutritional profile (Andersson et al., 2006; Regina et al., 2006) and reduce allergen levels (Le et al., 2006). Some prominently discussed RNAi-mediated products that have achieved market approval include the Flavr Savr ${ }^{\mathrm{TM}}$ tomato with reduced polygalacturonase expression for delayed fruit softening (Redenbaugh et al., 1992), Plenish ${ }^{\mathrm{TM}}$ soybean with reduced omega- 6 desaturase for high oleic acid content (EFSA GMO Panel, 2013) and Arctic $^{\mathrm{TM}}$ apple with reduced polyphenol oxidase expression for delayed browning (Sherman et al., 2015; Waltz, 2015).

The intended decrease in the expression of a target gene may require safety considerations on a case-by-case basis. For example, the purpose of soybean with reduced omega- 6 desaturase activity (also known as soybean 305423) is to obtain oil for frying and bakery with an increased content of heat-stable oleic acid (C18:1) at the expense of heat-labile polyunsaturated fatty acids (PUFAs) (C18:2 and C18:3). The consequences of this intended change in plant metabolism and composition need to be assessed to ascertain that the altered fatty acid profile does not impact on human and animal health in an exposure scenario where conventional vegetable oils are replaced with oil from soybean 305423 (EFSA GMO Panel, 2013). This assessment is focused on soybean oil and does not extend, for example, to soy milk and tofu for human consumption or defatted toasted meal for animal consumption, as such products are not expected to differ in composition between conventional soybean and soybean 305423, except for their altered fatty acid profile. However, the low contribution of fatty acids from these other soybean products to overall exposure is not anticipated to modify their nutritional impact. There is a detailed discussion of the risk assessment of an RNAi crop with altered metabolic composition in section 13.4.1, below.

\section{Unintended effects caused by silencing genes in plant metabolic pathways}

The engineering of plants with RNAi-mediated traits is achieved using the same transgenic techniques employed in the production of other GM crops grown and consumed widely today. In particular, RNAi plants are generated by inserting DNA sequences that lead to the expression of dsRNA or short hairpin RNA (shRNA), which are processed into siRNAs and microRNA (miRNA), respectively. These processed RNA molecules of 20-30 nt in length, collectively termed small RNA (sRNA), suppress gene expression at the transcriptional or post-transcriptional level, 
but are themselves designed to lack translation initiation signals and open reading frames necessary for protein biosynthesis (reviewed by Casacuberta et al., 2015; Petrick et al., 2013). Because the sRNA effectors are not translated to heterologous proteins, the risk assessment is focused on the direct and indirect consequences of the gene silencing machinery. The standard comparative analysis is well suited to detect possible unintended effects of RNAi-mediated silencing that may occur in addition to the intended gene expression changes.

An example of a potential indirect effect of RNAi-mediated silencing became apparent with the compositional analysis of the aforementioned high-oleic acid soybean 305423. In fact, the comparison between soybean 305423 and its non-GM (conventional) counterpart 'Jack' confirmed the expected change in fatty acid composition (increased levels of oleic acid at the expense of PUFAs), but also revealed an unexpected increase in the level of odd-chain fatty acids heptadecanoic acid (C17:0), heptadecenoic acid (C17:1) and nonadecenoic acid (C19:1). It is not known whether this effect results from off-target gene silencing (see below), from the manipulation of fatty acid synthesis pathways, from another unidentified response to the genetic modification, or as a consequence of either the simultaneous expression of a transgenic acetolactate synthase (ALS) enzyme (conferring herbicide tolerance) or the genetic background of the recipient soybean variety. In any case, a nutritional assessment came to the conclusion that the slight changes observed in the concentration of odd-chain fatty acids would not constitute a health hazard for humans and animals (EFSA GMO Panel, 2013).

\section{Unintended effects caused by off-target gene suppression}

In addition to the intended effects induced by expression of the non-coding RNA, unintentional changes may occur in the plant by suppression of genes that were not foreseen as RNAi targets. RNAi-mediated silencing is hybridizationdependent and therefore takes place in a sequence-specific manner. Nevertheless, suppression of genes with less than perfect sequence complementarity is possible (Senthil-Kumar and Mysore, 2011). In some cases, indications for such off-target effects may come from the screen for agronomic performance and phenotypic characteristics or from the compositional analysis (see section 13.2.5, below), as changes of gene expression may impact on one or more of these routinely measured parameters and analytes. Genome-wide bioinformatics studies retrieving transcripts that match the newly expressed sRNA sequences would potentially indicate possible off-target effects (see section 13.2.3, below, for appropriate bioinformatics tools). However, the genomes of typical crops are at best only partially sequenced and known reference genomes do not take into account the sequence variability occurring between varieties (Ramon et al., 2014; Casacuberta et al., 2015). Despite these limitations of bioinformatics-based predictions, whole-genome homology searches may nonetheless reveal unintended silencing targets.

The EFSA GMO Panel acknowledged the limitations of bioinformatics searches for possible off-targets of sRNA produced by GM plants. A predictive strategy is nevertheless possible, due to the fact that plant miRNAs are usually perfectly or nearly perfectly complementary to their target transcripts (Pačes et al., 2017). Thus, a set of parameters may allow for the prediction of RNAi off-targets in plants, whereas in humans and animals the extent of complementarity between the sRNA molecules and their targets is more flexible, thus preventing sufficiently reliable predictions (Pinzón et al., 2017). Besides the abundance of each sRNA produced, the degree and position of base pairing between the sRNA and the target mRNA are the primary factors determining the efficiency of silencing (Rhoades et al., 2002; Allen et al., 2005; Pasquinelli, 2012; Liu et al., 2014). Based on the current knowledge gained from the target specificity of natural miRNAs, the EFSA GMO Panel described in Annex II of the minutes of its 118th Plenary meeting (EFSA GMO Panel, 2017) a practical approach to identify sequences with potential off-target silencing. This procedure considers all $21 \mathrm{nt}$ sRNA sequences that derive from a given dsRNA precursor and comply with the following rules:

- No more than 4 base mismatches with no gap or 3 mismatches and one gap in 
the alignment between the 21-mer sRNA sequence and a potential target mRNA transcript, whereby each G:U base mispair counts as half a mismatch.

- Only one gap can be present in the sequence alignment between the 21-mer sRNA sequence and a potential target transcript, and this single gap cannot be longer than one nucleotide.

- The sequence alignment should not reveal any mismatches or gap at position 10/11 of the sRNA sequence.

- The sequence alignment should also not reveal more than two mismatches (or no more than one mismatch and one gap) in the first 12 nucleotides from the 5' end of the sRNA sequence.

- The minimum free energy of the imperfect duplex of the sRNA sequence with a potential target, divided by the minimum free energy of the perfect complement, should be $>0.75$.

The ensuing risk assessment of potential off-target silencing in the plant should consider the abundance and the number of different sRNAs showing relevant similarity to the same transcript, as the potential for gene repression increases with multiple sRNA sequences being able to bind to the same mRNA molecule (Hannus et al., 2014). Depending on the nature and function of the potential off-targets, the safety assessment may require extra studies in addition to the standardized agronomic/ phenotypic characterization and compositional analysis.

\subsubsection{Mechanisms and potential for non-target gene silencing in humans and livestock, including gut microbiome}

Mammals have an RNA silencing machinery, which is distinct from that of plants and other animal orders. While in plants there is a complex RNAi system with different types of siRNAs and Dicer proteins and a distinct miRNA pathway, mammals have a single set of Dicer and Argonaute (AGO) proteins for both miRNA and siRNA pathways (Pačes et al., 2017). This implies that in mammals siRNAs can function in the same way as miRNA, i.e. bind to mRNAs depending on homologies to the 'seed region' which comprises nucleotides 2-8 from the 5'end of the miRNA (Brennecke et al., 2005) and therefore have less strict target specificity than siRNAs in plants. In fact, in mammals sRNAs that are perfectly complementary to a target mRNA sequence are loaded into an AGO2 RNAinduced silencing complex (RISC) guiding target RNA cleavage, while siRNAs and miRNAs with minimum seed region homology are loaded on all four mammalian AGO proteins, resulting in translational inhibition (Meister et al., 2004; Gebert and MacRae, 2019). Lower requirements for sequence complementarities between miRNAs and mammalian mRNA make predictions of putative target sequences more difficult. As there is no distinct siRNA pathway in mammals, efficient induction of RNAi by long dsRNA, which has to be processed first into active siRNAs, is limited by poor Dicer activity in most mammalian cells (Nejepinska et al., 2012; Flemr et al., 2013; Pačes et al., 2017).

Another specific feature of plant siRNAs and miRNAs which distinguishes them from siRNAs and miRNAs in mammals is their 3'-terminal methylation at the 2'-hydroxyl group (Li et al., 2005; Yu et al., 2005). 3'-terminal methylation probably protects small RNAs from degradation (Li et al., 2005; Ren et al., 2014) and may promote recognition by plant Argonaute proteins in RISC (Yu et al., 2005). In contrast, mammalian AGO proteins preferably bind to non-methylated miRNAs (Tian et al., 2011). On the other hand, it was shown by Ma et al. (2004) that 2'-OH methylation only moderately decreased the binding affinity of siRNA for the PAZ domain of a human AGO protein, while binding was heavily reduced by most other $2^{\prime}-\mathrm{OH}$ modifications at the $3^{\prime}$-terminal nucleotide. In line with this, Chau and Lee (2007) found no obvious effect of $2^{\prime}-\mathrm{OH}$ methylation on the efficiency of silencing in mammalian cells. However, these authors also showed that siRNAs derived from a plant hairpin transgene and extracted from transgenic plants were not effective for gene silencing in mammalian cells. Among other things, they attributed this lack of cross-species function to a putative plant-specific siRNA modification.

These molecular mechanisms indicate that there is no evidence that plant-produced dsRNA 
and siRNAs are functional in mammalian cells. Another limiting factor is the high number of miRNAs required to exert an effect on gene expression (Brown et al., 2007). The expected unfavorable stoichiometry between exogenous small RNAs and mammalian mRNA targets will therefore further restrict gene silencing effects of dietary siRNAs in humans and livestock. In this context it also has to be mentioned that, in contrast to plants, fungi and nematodes, mammalian genomes do not possess an RNA-dependent polymerase (RdRP) homologue (Stein et al., 2003; Maida and Masutomi, 2011), implying that there is no amplification of ingested siRNAs and that each exogenous siRNA effector molecule would have to be delivered with the diet. Nevertheless, there is still some controversy about the bioavailability of relevant amounts of functional exogenous, plant-derived miRNAs in mammalian plasma and tissues and their possible effects on endogenous gene expression (Zhang et al., 2012b; Dickinson et al., 2013; Witwer et al., 2013; Pačes et al., 2017) (see sections 13.3.2 and 13.3.3, below).

If siRNAs from ingested food or feed stay intact after entering the digestive tract of humans and livestock, they may have effects on gut microbiota. Although RNA taken up by microorganisms is generally degraded and used for bacterial nutrition, there is some evidence that faecal miRNAs derived from mammalian gut epithelial cells penetrate gut bacteria and colocalize with bacterial nucleic acids (Liu et al., 2016). These authors showed that some of these miRNAs can regulate bacterial gene expression and thereby affect growth of certain bacterial species. Effects on gene expression in microorganisms encompassed decreases, as well as enhancements of transcripts, and were obviously distinct from RNA interference in eukaryotic organisms. Prokaryotes do not have an intrinsic RNAi machinery, but they produce non-coding sRNAs of around $100 \mathrm{nt}$ that can up- or downregulate mRNA stability and translation by base pairing to target mRNAs (Mayoral et al., 2014; Wagner and Romby, 2015). Although stemloop structures similar to eukaryotic precursor miRNAs have been detected for sRNAs from Wolbachia-infected insect cells and although sRNAs from these bacteria were shown to regulate expression of Wolbachia genes as well as expression of host genes (Mayoral et al., 2014), so far there is no evidence that plant-derived dietary miRNAs have an effect on the gut microbiome.

\subsubsection{Bioinformatics tools for prediction of off-target sequences of interfering RNA}

Bioinformatics tools are available that may help identify potential 'off-target' binding sites in the transcriptome of the recipient plant. However, these have not been specifically developed for the purpose of safety assessment of GM crops. Algorithms searching for off-target effects as part of the optimization of design of siRNA/ miRNA are offered as a single tool or, frequently, as part of a package. These include both accessible online web applications and open source, stand-alone software. Several of these tools predict which genes' mRNA transcripts will be targeted by sRNAs. The sequences of the latter can be entered by the user as such or as part of a larger cDNA sequence, often in FASTA format or with reference to a database accession. Such predictions assist in the selection and design of artificial siRNA or miRNA molecules that effectively bind a target with low off-target effects binding to mRNA transcripts of other genes (Lukasik and Zielenkiewicz, 2019). This also applies to the retrospective identification of targets of small RNAs that have been added to cells in massive functional screening experiments, i.e. 'miRNA screening', and have shown an effect (Lemons et al., 2013). The predicted targets can then be compared and confirmed with parallel data on downregulated genes from, for example, transcriptomics. Target-identifying tools can also be used for annotation, namely for genes encoding sRNA precursors in genomics data, or for sRNAs that have been identified in transcriptomics studies. Another common purpose includes, amongst others, investigation of isoforms (e.g. single-nucleotide polymorphisms (SNPs)) in naturally occurring sRNAs (Lukasik and Zielenkiewicz, 2019). A large number of such applications have been brought together in portals such as Tools4Mirs (https://tools4mirs. org/, accessed 30 March 2020), which harbours 170 tools, including 59 software items and ten websites that can be used for target prediction. The user could, for example, use multiple tools 
for target prediction to reach a 'consensus' outcome on the likeliest targets.

A basic approach to identify possible 'offtarget' genes for the siRNA/miRNA would be to search for sequence homologies between the cDNA sequence of interest and its counterparts from RNA transcriptome databases. Using BLASTn, for instance, the query sequence could be aligned with sequences from NCBI's RefSeq collections of mRNA transcripts from various organisms. The latter could contain data for the recipient plant species that has been genetically modified, or for humans, animals and other species representing environmental non-target organisms. The alignments in the BLAST outputs should then be judged for compliance with certain criteria that are known to affect the in vivo alignment and binding of mi/siRNA to the target mRNA within the RISC complex. For example, in animals a perfect match of the seed sequence of $6-8 \mathrm{bp}$ at the miRNA molecule's $5^{\prime}$ end is required. Some 'wobbly' mismatches are tolerated in this seed sequence but they decrease efficacy. Mismatches are also tolerated to a limited extent in the guide part of the miRNA molecule. These reportedly prevent degradation by Slicer but still block translation of the bound mRNA. Other factors include conserved residues and guanine-cytasine (GC) contents, amongst others, based on experience gained with miRNAs for certain species. Such factors affecting the efficacy of target binding and inhibition of gene expression are commonly automated as part of the specialized algorithms. These other factors are also relevant for the purpose of risk assessment, given that the seed sequence alone is relatively small (starting at $6 \mathrm{nt}$ ), which would easily render hundreds of genomic sequences that could be recognized but still remain without any major impact on gene expression.

Mainstream target prediction tool websites that specifically also focus on RNA targeting in plants include, for example, psRNATarget (Dai and Zhao, 2011) and TAPIR (Bonnet et al., 2010). On the psRNATarget website (http:// plantgrn.noble.org/psRNATarget/analysis\#, accessed 30 March 2020) users can enter the sequences of either the sRNA or target RNA and select various variables, such as the seed region (i.e. by default nt $2-13$ being recognized as critical in plants), the penalty for mismatches and opening gaps in the seed and other regions, and whether or not bulges or caps should be allowed in the structure of the miRNA-mRNA complex. The outputs thus list the various sRNAs or target genes, show the alignments with the matching parts of the sRNA and mRNA molecules compliant with the criteria and indicate whether the complex probably will be cleaved or inhibit translation. The algorithm underlying psRNATarget not only takes into account Crick-Watson base pairing using scoring matrices for matches, mismatches and gaps, but also features optionally an energy calculation for the unwinding of the adjacent RNA parts upon binding, which correlates with accessibility (Dai and Zhao, 2011).

Similarly, the TAPIR website offers a comparable search feature, yet both the miRNA and target sequences have to be entered at the same time. Variables that can be modified by the user include score and free energy, i.e. the binding energy of the mismatched sequences as compared with that of a perfectly matching pair.

Another tool that more specifically focuses on potential off-targets of small RNA in a wide array of organisms is pssRNAit (http://plantgrn.noble.org/pssRNAit/, accessed 30 March 2020). WMD3, a program for designing artificial miRNAs, also has a feature to BLAST a query sequence against DNA data sets from a large collection of plants (http://wmd3.weigelworld. org $/$ cgi-bin $/$ webapp.cgi? page $=$ Blast project $=$ stdwmd, accessed 30 March 2020).

\subsubsection{Possible non-specific effects of dsRNA and siRNA in mammals}

Molecules of dsRNA as well as the derived siRNAs, which constitute the molecular effectors of gene silencing in RNAi plants, occur naturally in food or feed and, therefore, constitute a ubiquitous component of the diet for both humans and animals. Systemic exposure following consumption of plants containing dsRNA or siRNA is limited in higher organisms by extensive denaturation and degradation of ingested RNA and by biological barriers preventing their cellular uptake. Inflammatory responses have been observed following systemic administration of siRNA in animal models (Judge and MacLachlan, 2008; Robbins et al., 2009). Such responses of the innate immune system are mediated by receptors that 
recognize nucleic acids such as Toll-like receptors (TLRs) or the RNA-binding protein kinase PKR. However, the observed inflammatory response might also be due to the delivery system or to chemical modifications introduced into the nucleic acid backbone to increase stability, rather than being elicited by the presence of native siRNA molecules (Heidel et al., 2004; Ma et al., 2005; Petrick et al., 2013). In any case, inflammatory reactions upon oral exposure to siRNA or other nucleic acids are not expected.

\subsubsection{Comparison of data requirements for safety assessment of food and feed from RNAi plants and from plants expressing recombinant proteins}

A universally accepted strategy is in place for the evaluation of the safety of GM crops and their products used as food or feed. This general approach, described in relevant documents issued by international organizations (Codex, 2003; ILSI, 2004; EFSA GMO Panel, 2011), analyses both the safety of intended effects introduced by the genetic modification and possible unintended effects resulting inadvertently from the new trait or from the genetic transformation process. A common cornerstone of all GM plant safety evaluation guidelines is the comparative assessment. This entails an extensive analysis comparing the GM crop with a genetically close, conventional counterpart with a history of safe use. Common, recurrent features of this analysis include the following.

- A molecular characterization of the inserted DNA including sequences introduced, their copy number, orientation, possible rearrangements, etc., as well as their expression (e.g. mRNA or NEPs) in different plant tissues and in different developmental stages, and stability of inheritance. For RNAi-modified crops, particularly relevant is the expression of the RNA encoded by the inserted genes, as well as the mRNA of the genes targeted for silencing, whilst no new proteins are expected to be expressed. Horizontal gene transfer, which also has to be assessed, may only be relevant if genes are introduced that convey a selective advantage to the recipient.

- An extensive comparative compositional analysis of the GM crop versus a conventional counterpart, grown in various locations representative of the conditions under which the crop is intended to be produced commercially. This quantitative analysis entails a wide range of macronutrients, micronutrients (e.g. vitamins, minerals), antinutrients and toxins, which are characteristic and relevant for the crop species and which are listed in consensus documents developed under the international frame of the Organization for Economic Co-operation and Development (for example, for maize composition see OECD, 2002). Despite considerable natural variability in nutrient/antinutrient content, the compositional analysis provides an indicator of possible unintended effects resulting from the genetic modification and, therefore, is also applicable to the risk assessment of RNAi plants. The outcome of this analysis should reflect the intended changes if the introduced trait is intended to affect plant composition, for example its fatty acid content (see section 13.4.1, below, for a specific case study).

- Phenotypic and agronomic characteristics of the crop are analysed in a similar way and this may reveal possible unintended changes caused by the genetic modification, as well as providing important data for the environmental risk assessment. The determination of agronomic/phenotypic characteristics may also help to confirm specific traits that are intended to improve plant growth, grain yield or protection from biotic and abiotic stresses (see section 13.4.2, below). Thus, this part of the comparative evaluation is also pertinent to the risk assessment of RNAi plants.

Based on these comparative tests, it can be decided if there is sufficient information to conclude the risk assessment or to proceed with assessment of additional data. Usually the items that are also addressed during risk assessment of GM crops include: (1) potential toxicity and allergenicity; and (ii) nutritional impact (Codex, 2003; EFSA GMO Panel, 2011; EC, 2013). 
For potential toxicity and allergenicity of NEPs and other compounds introduced or whose levels have been altered by the genetic modification, common items of the "weight of evidence' approach include a bioinformaticsbased comparison of the amino acid sequence of NEPs with those of known toxic and allergenic proteins. This is because all known food allergens are proteins, which raises the question as to whether any NEP could indeed become an allergen (or a toxin). The query sequences also include those that are hypothetically formed from open reading frames (ORFs) present in the insert and crossing its borders with the host's genomic DNA. This latter comparison would also still be applicable for hypothetical peptides encoded by the ORFs within the inserted construct encoding silencing RNA.

Other commonly assessed factors that are specific to proteins and not to non-coding RNA include:

- Information on the gene donor: is there a known history of toxicity or allergenicity, i.e. the propensity to cause toxic or allergic reactions? Is it known if these properties are linked with the product of the gene used?

- Resistance of NEPs to in vitro degradation by the digestive proteolytic enzyme pepsin, which indicates a greater likelihood of in vivo passage of the protein through the gastrointestinal tract, and possibility to cause toxicity or interact with the immune system in the consumer or animal.

- In vivo toxicity trials in laboratory animals with the NEPs or any other compound altered or introduced by the genetic modification and administered to the animals in purified form.

Toxicity testing with whole GM food and feed products in experimental animals should only be performed as a last resort given the inherent insensitivities and other practical and ethical limitations, and with a clear hypothesis of potential adverse effects. Nevertheless, a unique feature of the European legislation is the mandatory requirement for 90-day feeding studies, which need to be provided even in the absence of any hazard or risk hypothesis (Devos et al., 2016). For food allergenicity testing, there are no validated animal models yet.
The nutritional impact of any intended and unintended changes in the nutrient profile of the host crop caused by the genetic modification may be particularly relevant if there are substantive changes in nutrient levels (e.g. beyond background variability) and if the particular crop is known to be a relevant source of the specific nutrient. In such cases, it should be estimated to what extent these changes will affect the intake of the particular nutrient by consumers and domestic animals. To estimate the intake, the quantitative data on the altered nutrient levels from the compositional analyses need to be combined with data on the intake of the crop and derived product, such as from the EFSA Food Consumption Database. In some rare cases, it may be necessary to extend the data with new studies in representative animal models.

In summary, the paradigm of comparative assessment is well suited for the safety evaluation of RNAi plants. Unlike the vast majority of GM crops currently on the market, which have been designed to express heterologous proteins (so-called NEPs) that confer a desired phenotype like herbicide tolerance, pest protection or increased yield, RNAi-mediated traits involve the expression of non-coding RNA without NEP biosynthesis. Therefore, NEP-related aspects of the safety assessment process are not applicable. This includes the search for homology of NEPs with known protein toxins and allergens, their digestibility (as allergenic or toxic proteins may be refractory to degradation by digestive enzymes) and, in the absence of a proven history of safe use, rodent studies to test the potential oral toxicity of NEPs. However, in order to predict unintended effects from off-target gene silencing, EU Regulation No. 503/2013 requests that for the authorization of RNAi plants in the EU an in silico bioinformatics analysis is carried out to identify potential off-target genes in the plant genome (EC, 2013).

Any additional studies considering intended or unintended effects of sRNA should be considered as needed on a case-by-case basis. For example, the use of RNAi as an insecticidal tool raises the question of whether sRNAs that are lethal to insects could also harm humans and farm or companion animals. There is a detailed discussion of the risk assessment of an RNAi crop conferring insecticidal properties in section 13.4.2, below. 


\subsection{Exposure Assessment}

\subsubsection{Expression level of dsRNA and siRNAs in plants}

The first determinant for exposure of humans and farm animals to siRNAs from consumption of plant-derived food or feed is the level of dsRNA expression in the respective GM RNAi crop which provides the basis for a maximal estimate for exposure, assuming a worst-case scenario with no barriers to bioavailability. The expression level of transgenes in different plant tissues is dependent on the regulatory sequences, but may also be affected by environmental changes and the age of the plant (Meyer et al., 1992; van der Hoeven et al., 1994). Transgenes including dsRNA constructs introduced into GM plants are often under control of a strong constitutive promoter like the cauliflower mosaic virus $35 \mathrm{~S}$ promoter (P35S), accounting for a high constitutive expression in all plant tissues. Nuclear expressed dsRNA, however, is to a large part processed in plant cells into siRNAs by Dicer-like (DCL) proteins from the plant RNAi machinery (Chau and Lee, 2007; Frizzi and Huang, 2010; Zhang et al., 2015). Thus, when quantifying specific RNA levels relevant for dietary intake, both dsRNA and siRNAs have to be taken into account. Chau and Lee (2007) found that in transgenic tobacco plants expressing a hairpin construct under P35S control, the hairpinspecific siRNA level was about $50 \mathrm{ng} / \mathrm{g}$ leaf tissue. Petrick et al. (2013) calculated a daily dietary exposure to transgene-derived siRNA from a putative RNAi soybean product of $45 \mu \mathrm{g} / \mathrm{kg}$ for adults, assuming a transgene-derived siRNA rate of $1.5 \%$ of the total RNA and a maximum amount of total RNA in grain tissue of $986.6 \mu \mathrm{g}$ RNA/g. However, this transgene-specific siRNA percentage and the resulting exposure estimate seems to be too high. Ivashuta et al. (2009) reported endogenous small RNAs (21-24 nt) as a whole to be present at levels of maximally $1.61 \mu \mathrm{g} / \mathrm{g}$ soybean grain, which corresponds to clearly less than $1.5 \%$ of total plant RNA, with similar levels found in conventional maize and rice grain. Using a validated quantification assay based on the QuantiGene Plex 2.0 (Affymetrix) technology (Armstrong et al., 2013), Bachman et al. (2016) detected DvSnf7 dsRNA in transgenic insecticidal maize MON 87411 at levels up to $0.17 \mathrm{ng} / \mathrm{g}$ dry weight in grain, while the mean level in leaf was $14.4 \mathrm{ng} / \mathrm{g}$ fresh weight. There was no information, though, on the proportions of long dsRNA originating from the transcript versus small siRNAs resulting from DCL processing.

For RNAi plants conferring resistance against certain insects via host-induced gene silencing (HIGS), for example MON 87411 expressing dsRNA targeting an essential insect transcript, it has to be considered that dsRNAs require a certain minimal length in order to be taken up efficiently and become biologically active in insects (Bolognesi et al., 2012). This implies that processing of dsRNA into siRNAs, which has been shown to occur readily for nuclear expressed dsRNAs, needs to be kept at a minimum. This is especially important for certain insect groups like Lepidoptera, which are less susceptible to RNAi (Terenius et al., 2011) and therefore require delivery of a very large amount of dsRNA to be efficiently targeted. One way to prevent the rapid turnover of dsRNAs in plants is the construction of transplastomic plants where dsRNA accumulates in the chloroplasts, thereby being protected from Dicer (Zhang et al., 2017). In contrast to nuclear transformants, no detectable levels of siRNAs were found in transplastomic Nicotiana benthamiana plants, but only large amounts of the unspliced hairpin RNA (Bally et al., 2016). Similar results were obtained by Zhang et al. (2015) for tobacco and potato lines expressing insect gene-specific dsRNAs from the plastid genome. Moreover, differences between plant tissues were reported. While in transplastomic potatoes specific dsRNA transcripts were below the detection limit in tubers, levels of insect gene-specific dsRNAs up to $0.4 \%$ of the total cellular RNA accumulated in leaves (Zhang et al., 2015). Assuming a total RNA amount of around $500 \mu \mathrm{g} / \mathrm{g}$ leaf tissue, this corresponds to $2 \mu \mathrm{g}$ of dsRNA, which is about 150-fold higher compared with the amount of DvSnf7 dsRNA reported by Bachman et al. (2016). Transplastomic crop plants are thus distinct from nuclear transformants due to the restriction of substantial dsRNA production 
to chloroplast-containing photosynthetic tissues and due to deviant amounts of dsRNA and siRNAs.

\subsubsection{Oral exposure from dietary intake}

All foods and feeds contain naturally occurring coding and non-coding RNA, but animal tissues generally have a higher RNA concentration than plants (Jonas et al., 2001). The overall content of RNA in plant-derived food and feed is in the order of $1 \mathrm{mg} / \mathrm{g}$ tissue, but up to $95 \%$ by weight of this total amount consists of highly abundant transfer RNA (tRNA), ribosomal RNA (rRNA) and mRNA. As outlined above, siRNA and miRNA make up less than 5\% of the RNA content of plant tissues. Although present at such minor levels, siRNA and miRNA sequences found in plant tissues (for example, cereal or soybean seeds) display a high similarity or even identity to genomic regions of humans and livestock animals (Lassek and Montag, 1990; Heisel et al., 2008; Ivashuta et al., 2009). This observation opens the possibility that dietary sRNA, of natural occurrence or inserted into RNAi plants, may elicit biological responses in humans or animals. It should be noted, however, that even with the usually intended overexpression of the transgene-derived sRNA in RNAi plants, this additional sRNA represents only a very minute fraction of the total dietary RNA occurring in food and feed.

Many lines of evidence demonstrate that the mammalian digestive tract provides an extremely effective barrier to the local or systemic uptake of exogenous RNA molecules, which are inherently unstable in their natural form. First, the degradation of ingested RNA begins in saliva, which is a rich source of ribonucleases (Bardoń and Shugar, 1980; Park et al., 2006). Secondly, the harsh milieu in the stomach with low $\mathrm{pH}$ promotes further RNA degradation as well as depurination (Loretz et al., 2006; O'Neill et al., 2011). The dominant gastric enzyme pepsin, which was thought to be protein-specific, has been shown to digest effectively nucleic acids including RNA (Liu et al., 2015). Thirdly, pancreatic nucleases, phosphodiesterases and nucleoside phosphorylases, secreted into the intestinal lumen, degrade ingested RNA into oligonucleotides, nucleotides and free bases (Jain, 2008; O'Neill et al., 2011). Also, the intestinal epithelium, like any other cellular membrane, presents a physical barrier to hydrophilic compounds like nucleic acids (Khatsenko et al., 2000). Any RNA that may bypass cellular membranes by transport into intestinal cells through endocytosis will be targeted to endosomal vesicles, sequestered into lysosomes and thereby degraded by lysosomal nucleases (Gilmore et al., 2004). Thus, the systemic absorption of orally ingested RNA is negligible. For a 20mer DNA oligonucleotide, constructed with stabilizing phosphorothionate linkages to prevent degradation in the gastrointestinal tract, oral bioavailability in rats was at best $0.3 \%$ after gavage administration (Nicklin et al., 1998). Kendal D. Hirschi and colleagues reported on an unusual sRNA from herbs, flowers and vegetables with a comparably high stability in gastrointestinal fluids (Yang et al., 2016, 2018). This atypical sRNA of $20 \mathrm{nt}$, denoted as MIR2911 although it is a product of $26 \mathrm{~S}$ rRNA breakdown, arises abundantly from ribosome degradation in macerated plant tissues. When tested in cabbage extracts, around $0.1 \%$ of input MIR 2911 survived a 60 min in vitro incubation in gastrointestinal fluid, whereas for comparison MIR168 (see below) was digested under identical conditions around 1000 times more efficiently. MIR2911 was reported to occur at femtomolar concentrations in the plasma of rodents fed vegetable-enriched diets and was found in human plasma (Yang et al., 2015a, Yang et al., 2015b), where it appears to be stabilized against degradation and elimination by some host factors (Yang et al., 2016, 2017,2018 ). However, a follow-up report considered that MIR2911 was probably misidentified in human plasma as a plant-derived sRNA, but instead matches human genome sequences (Witwer, 2018).

Other authors found only trace levels at best of exogenous dietary miRNA molecules in the plasma of mice or humans (Chen et al., 2013; Snow et al., 2013; Dickinson et al., 2013; Witwer et al., 2013; Huang et al., 2018), confirming the generally ineffective uptake and transfer of miRNA from food or feed to recipient organisms. A major problem is the use of exceptionally sensitive methods allowing for the detection of few nucleic acid molecules, which gives rise to false positive results due to non-specific amplification or sample 
contamination (Zhang et al., 2012a; Tosar et al., 2014). A survey of publicly available sequencing data sets found foreign miRNA in human body fluids and tissues, although at low abundance. Intriguingly, there is no enrichment of foreign RNA in human tissues that are most directly exposed to dietary intake, like liver, and there is no depletion of foreign sequences in compartments that are comparably well separated from the bloodstream, like for example the brain. The majority of foreign miRNA detected in this survey originates from rodents, which are common laboratory animals but do not contribute to human nutrition. It was, therefore, concluded that the apparent detection of foreign sRNA sequences in mammalian/human body fluids or tissue results from technical artifacts or misidentification (Kang et al., 2017; Witwer, 2018).

The detection of plant-derived or other dietary sRNA entering the bloodstream of animals or humans (see for example Zhang et al., 2012b; Yuan et al., 2016) is prone to artifacts and fails independent experimental reproduction, and the general consensus is that only a very small fraction, if any, of ingested sRNA will be absorbed into the circulation. Additionally, minor traces of sRNA that might be absorbed into the blood are not spared from degradation and excretion. For siRNA molecules, a rapid breakdown in human plasma has been described with nearly $75 \%$ degradation within 2 min of incubation (Layzer et al., 2004). Samples of siRNA injected intravenously into mice exhibited a short half-life in the range of only a few minutes and were subject to rapid hepatic and renal clearance (Vaishnaw et al., 2010; Christensen et al., 2013). It can be concluded from the above findings that plant sRNA molecules never reach sufficiently high concentrations and stability to exert biologically relevant effects in mammals and humans. In the unlikely event that traces of ingested RNA molecules are absorbed from the gastrointestinal tract, not degraded within the cardiovascular system and not readily eliminated through the liver or kidneys, these remaining RNA molecules, in the absence of any delivery vehicle and amplification mechanism, would not be able to cross lipid membranes, escape lysosomal degradation and, hence, reach the cytoplasm of cells (Sioud, 2005; Manjunath and Dykxhoorn, 2010). Taken together, the instability in biological fluids and matrices, in combination with biological barriers, reduces the likelihood that ingested sRNA will display local or systemic biological activities in mammals and there is currently no reason to believe that this conclusion may not also apply to other vertebrates, including birds and fish (EFSA GMO Panel, 2018). There is also no basis for the hypothesis that engineered sRNA in GM feed and foods may develop different nutritional properties than the background of natural sRNAs already present in all GM and conventional crop.

\subsubsection{Likelihood of transfer of dsRNA or siRNA from plant to mammalian cells}

Mammalian cells do not efficiently take up dsRNA or sRNA. The genetic basis for RNA uptake mechanisms has been investigated in detail in the nematode Caenorhabditis elegans. RNAi-mediated gene silencing is induced by soaking worms in siRNA-containing solutions (Tabara et al., 1998; Maeda et al., 2001) or by feeding them with bacteria that express dsRNA (Timmons et al., 2001; Newmark et al., 2003). A straightforward RNA uptake in C. elegans is mediated by transmembrane protein channels like SID-1, SID-2 and SID-5 (SID, systemic RNA interference-deficient) that promote RNA endocytosis, transfer of RNA into the cytoplasm of cells and RNA spread from cell to cell (Winston et al., 2002, 2007; Feinberg and Hunter, 2003; Jose and Hunter, 2007; McEwan et al., 2012). Two mammalian proteins, referred to as SIDT1 and SIDT2 (SID transmembrane family member 1 and 2), have been annotated as homologues of the RNA transporter SID-1. However, these mammalian proteins have more similarity with the C. elegans cholesterol uptake protein CHUP-1 than with SID-1. Also, SIDT1 and SIDT2 contain putative cholesterol-binding motifs known as cholesterol recognition/interaction amino acid consensus (CRAC) domains. Accordingly, the expression of SIDT1 and SIDT2 in human cells in culture demonstrated that they function as transmembrane cholesterol transporters, but are unable to mediate the intracellular uptake of dsRNA or miRNA (Méndez-Acevedo et al., 2017). Another aspect of RNAi observed in C. elegans is the amplification of sRNA, a mechanism that is restricted to plants, fungi, some nematodes and some other invertebrates. 
Amplification takes place when sRNA molecules hybridize to target RNA sequences and prime these targets to be copied by RNA-dependent RNA polymerase (RdRP) (Hunter et al., 2006; Mittelbrunn and Sánchez-Madrid, 2012). Such an amplification of sRNA is absent in insects and vertebrates, including mammals and humans (Tomari and Zamore, 2005; Miller et al., 2012).

Nonetheless, reports from the Nanjing University in China suggested that natural plant miRNA, once ingested by animals or humans, may exert local activities in the intestinal mucosa and even systemic effects. The authors switched the regular feed of mice to a diet consisting entirely of unprocessed rice and, already 3-6 h later, detected several rice miRNAs at femtomolar concentrations in the bloodstream and liver (Zhang et al., 2012b). One of these detected miRNAs (miR168a) displays sequence identity with a region of the mouse gene coding for LDLRAP1 (low-density lipoprotein receptor adapter protein 1). Although the respective mRNA was not affected following the consumption of rice, the authors reported that the level of LDLRAP1 protein was lower in the liver of mice fed rice than in controls receiving a standard rodent diet. The authors also reported elevated LDL-associated cholesterol levels in plasma and attributed this effect to the suppressed LDLRAP1 expression resulting from miR 168 a uptake. This finding is contradicted by a 90-day feeding study as well as by a three-generation study, both with a $70 \%$ inclusion of rice into the diet of rats. In these studies, no LDL changes were detected relative to control groups (Zhou et al., 2011, 2012). Another study, published by Dickinson et al. (2013), attempted to replicate the findings of Zhang and colleagues. After feeding mice with rice-containing diets at an inclusion rate of up to $75 \%$, these authors detected only trace levels, if any, of plant-derived miRNA molecules in plasma. Zhang et al. (2012a) also described the presence of miR168a in the serum of Chinese persons with high dietary intake of rice. However, traces of plant-derived siRNA or miRNA taken up into the cells of the gastrointestinal epithelium, or systemically absorbed, would not be sufficient in terms of their concentration to trigger the gene silencing machinery or exert any other biologically relevant effect. In summary, humans and farm or companion animals do not have the mechanisms to take up and amplify dietary RNA in a way that their genes would be subjected to foreign sRNA-mediated regulation. Given the history of safe consumption of nucleic acids including RNA, oral toxicity studies of dsRNA and derived sRNA are currently not warranted (EFSA GMO Panel, 2018).

\subsection{RNAi-specific Risk Assessment}

In view of the above considerations, there is no reason to expect that GM plants tested in depth by the usual comparative and, if necessary, nutritional assessments are any less safe than conventional comparators just because a particular trait is generated by the RNAi pathway. This conclusion is supported by two specific examples outlined below.

\subsubsection{Case study of an RNAi crop with altered metabolite composition}

RNAi-based GM crops that have previously been filed for regulatory approval, particularly in North America but also elsewhere, include papaya, potato and cucurbits with transgenes aimed at silencing genes of invading viruses, and maize with resistance against an infesting insect (corn rootworm). In addition to these crops, GM soybean and potato that had been modified with silencing constructs targeting endogenous genes involved in biosynthesis of fatty acids and starch as well as apple and tomato for the suppression of plant genes involved in enzymatic browning (polyphenol oxidase) and ripening (polygalacturonidase), respectively, have been submitted for approval. A case in point for such compositionally altered crops is high-oleic soybean, which will be explored in further detail in this section. Whilst the risk assessment of this crop included the regular, recurrent items summarized in section 13.2.5 above, we will discuss here some features that were specific to this type of compositionally altered RNAi crop.

The modification in soybean 305423 targeted the biosynthesis of PUFAs. PUFA biosynthesis includes several subsequent steps of enzymatic dehydrogenation, which introduces double bonds in the carbon chain of the fatty acid, hence the 'unsaturation'. Oleic acid 
(C18:1), for example, is the mono-unsaturated form of stearic acid (C18:0) with a backbone chain of 18 carbon atoms length, and a double bond between the 9th and 10th carbon atoms (C9-C10). It is a substrate for the fatty acid dehydrogenase enzyme FAD2 (oleoyl phosphatidylcholine dehydrogenase). Its FAD2-2 and FAD2-3 isomers are constitutively expressed throughout the plant, whilst FAD2-1 is strongly expressed during embryogenesis in seeds. FAD2 converts oleic acid to the PUFA linoleic acid (C18:2), by introducing a second double bond between the 12 th and 13th carbon atoms. Linoleic acid, in turn, can be further enzymatically transformed to the PUFA linolenic acid (C18:3) with three double bonds.

For industrial purposes, such as for frying and bakery, it is desirable to increase the oxidative stability of PUFA-rich vegetable oils. This can be done by decreasing the content of PUFAs, which are particularly prone to oxidation. This way, the oils will tend to become rancid less quickly. Whilst catalytic hydrogenation was historically used for this purpose, there are potential consumer health issues with the transfatty acids that may be formed during this process. As an alternative, the use of high-oleic acid mutants of oilseed crops with decreased levels of PUFAs would help to avoid these issues.

Around the globe, for example, there is widespread cultivation of high-oleic sunflower varieties, which originate from a mutant created through chemical mutagenesis, in which the FAD2-1 gene has been partially duplicated, causing gene silencing (Schuppert et al., 2006). Also, transgenesis exploiting RNA interference has been applied to introduce constructs silencing expression of FAD2-1 in experimental and commercial oilseed crop lines. Examples include soybean, cotton, Indian mustard, carinata, flax and camelina (Kinney and Knowlton, 1998; Chapman et al., 2001; Sivaraman et al., 2004; Du et al., 2018). A more recent, pre-commercial example is super high-oleic safflower, which has been modified with transgenes encoding hpRNAs that target the FAD2-2 and FATB genes (Wood et al., 2018). Genome editing using TALENs or CRISPR-Cas9 has also been applied to achieve similar results, introducing mutations in FAD2 genes to create high-oleic variants of oilseed rape, rice and soybean, for example (Haun et al., 2014; Abe et al., 2018; Okuzaki et al., 2018; Al Amin et al., 2019). A genomeedited soybean line with deletions created with TALENs in the FAD2-1 gene was recently introduced into the US market, and its oil is offered to the food industry under the trade name 'Calyno ${ }^{\circledR}$ ' for frying and dressing, and use as a sauce (FDA, 2019).

As an example of a risk assessment of high-oleic soybean, transgenic GM soybean line 305423 (tradename 'Plenish $\AA^{\text {') }}$ assessed by the EFSA GMO Panel contained two types of modifications, namely: (i) a gene-silencing construct targeting the FAD2-1 gene imparting the higholeic phenotype; and (ii) the ALS gene encoding a mutant acetolactate synthase (ALS) gene mediating resistance to ALS-inhibiting herbicide active substances.

With regard to safety, soybean 305423 had to be assessed as a GM crop, in line with the internationally harmonized principles of comparative safety assessment. Soybean 305423 had been transformed with a DNA construct containing a partial sequence of the soybean fad21 gene aimed at silencing the expression of the host's endogenous counterpart. This gene was under the control of the promoter and terminator sequences from the Kunitz trypsin inhibitor gene 3 (Kti3) coding for the antinutrient and allergenic trypsin inhibitor protein, thus allowing for seed-specific expression of the inserted genes. The inserted DNA also carried the gm-hra gene encoding an ALS enzyme conferring herbicide resistance (EFSA GMO Panel, 2013).

Molecular characterization of soybean 305423 showed that DNA had been inserted at four distinct sites, with a relatively complex pattern comprising, for example, seven copies of the fad2-1 fragment and five of the KTi3 terminator. Expression data (Northern blotting) indeed showed inhibited expression of fad2-1 in seeds of soybean 305423 as well as of KTi3 as a corollary effect. The latter can be attributed to silencing caused by the presence of KTi3-related sequences (promoter, terminator) in the introduced DNA. Bioinformatics-supported comparisons of the amino acid sequences hypothetically formed from the ORFs of the inserts and flanks with known toxic and allergenic proteins did not reveal any relevant similarities. An experiment testing the stability of inheritance indicated recombination between the KTi3 promoter elements at one of the integration sites in a single 
progeny plant, accounting for loss of the gm-hra gene cassette, but this was not considered as relevant for safety assessment (EFSA GMO Panel, 2013).

Compositional analysis of seeds from experimental field sites showed that, whilst nontransgenic soybeans contained $19 \%$ oleic acid, $55 \%$ linoleic acid and 8\% linolenic acid, these figures had markedly changed in 305423 soybeans to $73 \%(+54 \%), 4 \%(-5 \%)$, and $4 \%(-4 \%)$, respectively. This confirmed that the fatty acid composition had indeed changed from a preponderance of the PUFAs linoleic and linolenic acids to that of the MUFA oleic acid, as intended (EFSA GMO Panel, 2013).

The potential nutritional impact of these changes was assessed, taking into account that consumers need to attain adequate intakes of linoleic and linolenic acids. It was assumed that the new oil from soybean 305423would totally replace conventional vegetable oils in targeted foods. Based on consumption data, the intakes of the various types of fatty acid by different consumer groups, ranging from toddlers to elderly people, were estimated. The reductions in PUFA intakes thus obtained under these conservative scenarios did not raise health concerns, though post-market monitoring for verification of these consumption data was also recommended (EFSA GMO Panel, 2013).

In conclusion, the risk assessment of soybean 305423 as an example of a crop with silenced endogenous genes shows that various generic factors come in play. This could also be translated to other traits achieved through RNAi, such as disease resistance based on suppression of the plant host's intrinsic vulnerability factors. For example, Northern blotting or other means of RNA expression analysis will be important to confirm the targeted suppression of the endogenous gene of interest. Moreover, it should be verified if endogenous genes bearing similarity with inserted elements (such as observed for KTi3 on soybean 305423) are also affected, though not the aim of the modification, as a corollary effect. Bioinformatics-supported comparisons of the amino acid sequences of peptides that could be hypothetically formed from ORFs with sequences of allergenic and toxic proteins will help to identify potential safety issues should the inserted DNA sequences unexpectedly be translated into peptides. Extensive comparative analysis of compositional, phenotypic and agronomic characteristics will help to identify any potential intended and unintended effects of the modification. For the changes identified, the impact on toxicity, allergenicity and nutritional value of the modified RNAi crop should be assessed.

\subsubsection{The case of insecticidal RNAi maize}

RNAi-mediated silencing, first observed in nematodes and plants (Dougherty et al., 1994; Fire et al., 1998; Brodersen and Voinnet, 2006; JonesRhoades et al., 2006; Vazquez, 2006), was later demonstrated also in some insects (Ghildiyal et al., 2008). Several reports demonstrated the proof-of-principle that it is possible to induce an RNAi-mediated suppression of essential genes by feeding parasitic nematodes (Huang et al., 2006; Yadav et al., 2006; Fairbairn et al., 2007) or the larvae of insect pests with GM plants engineered to express specific dsRNA precursors (Baum et al., 2007; Mao et al., 2007). In maize MON 87411, this principle is employed for the management of western corn rootworm (WCR), Diabrotica virgifera virgifera, the most important maize pest in the US 'corn belt'. A single insert has been introduced to express a modified version of Bacillus thuringiensis Cry3Bb1 protein, a glyphosate-tolerant 5-enolpyruvylshikimate3-phosphate synthase (EPSPS) enzyme and an expression cassette containing two sequences of the D. virgifera (Dv)Snf7 gene coding for an essential vacuolar sorting protein. The reader is referred to the relevant scientific opinion of the EFSA GMO Panel for the risk assessment of the Cry3Bb1 and EPSPS proteins (EFSA GMO Panel, 2018). The Snf7 dsRNA expression cassette consists of two fragments of the coding sequence of the DvSnf7 gene in an inverted repeat configuration flanked by the e $35 \mathrm{~S}$ promoter from cauliflower mosaic virus, the heat shock protein 70 intron from Zea mays and the 3' untranslated sequence of the $E 9$ gene from Pisum sativum. The DvSnf7 inverted repeat sequence generates a $240 \mathrm{bp}$ precursor with hairpin structure that is processed to generate siRNA molecules. When the WCR larvae feed on MON 87411 maize, silencing of the DvSnf7 gene leads to insect lethality, thus protecting the plant from root damage. 
The mechanism of RNA uptake and systemic spread in the WCR is poorly understood but may involve SID-like (SIL) proteins and also clathrinmediated endocytosis. An RdRP-mediated amplification is absent in the WCR (Huvenne and Smagghe, 2010; Fishilevich et al., 2016).

As outlined in section 13.2.1 above, in the EU a bioinformatics analysis is required according to Regulation (EU) No. 503/2013 to identify potential off-target genes that may be influenced in their expression by the siRNA approach. Following the recommendations of the EFSA GMO Panel for an RNAi off-target search in plants, it was found that none of the maize transcripts in the available databases showed perfect match to any of the siRNAs possibly produced. A few maize transcripts have sequences matching the siRNAs with one to four mismatches. Some of these sequences presented matches for more than one (up to five) possible siRNA. However, a scrutiny of the anticipated function of the proteins encoded by these mRNAs matching the siRNA sequences indicated that off-target effects, if they took place, would not raise safety concerns, because the possible depletion of these potential targets is not expected to affect agronomic, phenotypic, compositional and nutritional characteristics of the GM maize. This conclusion is confirmed by the comparative analysis of maize MON 87411 and non-GM comparators. A field trial for the assessment of agronomic and phenotypic characteristics did not reveal any statistically significant differences between maize MON 87411 and this conventional counterpart. Also, no changes in the composition of grains were detected, i.e. concentrations of none of the 78 tested maize constituents were significantly different in maize MON 87411 compared with its conventional counterpart and also present at levels outside the equivalence range defined by non-GM reference varieties grown in the same field trial. Of course, an off-target gene silencing may also theoretically occur in organisms exposed to the RNAi plant, for example upon food and feed consumption. As described in sections 13.3.2 and 13.3.3 above, dietary dsRNA and sRNA are, however, rapidly denaturated, depurinated and degraded after ingestion, due to the particular milieu of the gastrointestinal tract and the presence of multiple digestive enzymes in humans, mammals and other vertebrates. Further biological barriers like cellular membranes or lysosomes limit the uptake of dsRNA and sRNA. Therefore, it is not expected that sRNAs with DvSnf7 sequences are able to exert any biological effects once maize MON 87411 is ingested by humans, or by farm or companion animals (EFSA GMO Panel, 2018). A 28-day oral repeated-dose study in mice with DvSnf7 dsRNA, conducted in accordance with the principles laid down in the OECD Test Guideline 407, lends further support to the above conclusion. In this study, the DvSnf7 dsRNA was administered by daily oral gavage at doses of 1,10 and 100 $\mathrm{mg} / \mathrm{kg}$ body weight. No treatment-related effects were observed in the animal body weights, food intake, clinical parameters, clinical chemistry values, haematology, gross pathology and histopathology (Petrick et al., 2016). Considering the possible Snf7 dsRNA and sRNA content of maize MON 87411, which is difficult to assess quantitatively, the authors of this toxicity study calculated that a human would need to eat 60 million kilograms of maize MON 87411 per day to reach the dose of $100 \mathrm{mg} / \mathrm{kg}$ body weight that in the mouse study remained without any effects. The lack of biological activity of ingested dsRNA or sRNA is also documented by a previous 28 -day toxicity study in mice using dsRNA of $218 \mathrm{bp}$, or a pool of four 21-mer siRNA molecules, targeting a mouse vacuolar ATPase transcript. The daily dose administered by gavage was $64 \mathrm{mg} / \mathrm{kg}$ for the dsRNA and 48 $\mathrm{mg} / \mathrm{kg}$ for the siRNA. This 28 -day toxicity study revealed no adverse effects and, importantly, no changes of vacuolar ATPase expression in any tissue, including the gastric mucosa (Petrick et al., 2015), thus supporting the notion that no consequences are expected from the dietary uptake of dsRNA or siRNA present in food or feed. Taking into account all of the above, maize MON 87411 is considered equivalent, with respect to its food and feed safety and its nutritional profile, to non-GM maize counterparts.

\subsection{Conclusion}

The concept of gene silencing in GM plants based on the principles of RNAi has been exploited from the early days of commercial crop biotechnology. Applications straddle traits of both agronomic importance, such as disease and pest resistance, and of consumer and producer 
benefit, such as oilseeds with altered fatty acid composition. The internationally harmonized risk assessment approach for the food safety of GM crops can also be applied well to the subcategory with RNAi-based gene-silencing traits, notwithstanding some special features, such as the lack of newly expressed proteins. Moreover, the issues of off-target effects of the silencing RNAs within the plant, as well as the hypothetical uptake by consumers after ingestion of foods derived from RNAi-based GM crops, has been at the focus of scientific discourse. The current state of knowledge indicates that crosskingdom interactions of consumed plant sRNA with the intrinsic RNAi machinery of humans and farm animals is a highly remote possibility at best, with unlikely impacts of any potential health concern. The featured case studies both underscore the applicability of current guidelines of the EFSA GMO Panel, enshrined in Implementing Regulation No. 503/2013, and more generally, those of the international Codex Alimentarius of the FAO/WHO Food Standards Programme.

\section{Acknowledgement}

Financial support from the Dutch Ministry of Agriculture, Nature, and Food Quality under the Statutory and Supportive Tasks program (WOT-2) for GK's contribution is gratefully acknowledged.

\section{References}

Abe, K., Araki, E., Suzuki, Y., Toki, S. and Saika, H. (2018) Production of high oleic/low linoleic rice by genome editing. Plant Physiology and Biochemistry 131, 58-62. DOI: 10.1016/j.plaphy.2018.04.033.

Al Amin, N., Ahmad, N., Wu, N., Pu, X., Ma, T. et al. (2019) Crispr-Cas9 mediated targeted disruption of FAD2-2 microsomal omega-6 desaturase in soybean (glycine max.L). BMC Biotechnology 19(1), 9. DOI: 10.1186/s12896-019-0501-2.

Allen, E., Xie, Z., Gustafson, A.M. and Carrington, J.C. (2005) MicroRNA-directed phasing during transacting siRNA biogenesis in plants. Cell 121(2), 207-221. DOI: 10.1016/j.cell.2005.04.004.

Andersson, M., Melander, M., Pojmark, P., Larsson, H., Bülow, L. et al. (2006) Targeted gene suppression by RNA interference: an efficient method for production of high-amylose potato lines. Journal of Biotechnology 123(2), 137-148. DOI: 10.1016/j.jbiotec.2005.11.001.

Armstrong, T.A., Chen, H., Ziegler, T.E., Iyadurai, K.R., Gao, A.-G. et al. (2013) Quantification of transgene-derived double-stranded RNA in plants using the QuantiGene nucleic acid detection platform. Journal of Agricultural and Food Chemistry 61(51), 12557-12564. DOI: 10.1021/ jf4031458.

Bachman, P.M., Huizinga, K.M., Jensen, P.D., Mueller, G., Tan, J. et al. (2016) Ecological risk assessment for DvSnf7 RNA: a plant-incorporated protectant with targeted activity against western corn rootworm. Regulatory Toxicology and Pharmacology 81, 77-88. DOI: 10.1016/j.yrtph.2016.08.001.

Bally, J., McIntyre, G.J., Doran, R.L., Lee, K., Perez, A. et al. (2016) In-plant protection against Helicoverpa armigera by production of long hp RNA in chloroplasts. Frontiers in Plant Science 7(e47534), 1453. DOI: 10.3389/fpls.2016.01453.

Bardoń, A. and Shugar, D. (1980) Properties of purified salivary ribonuclease, and salivary ribonuclease levels in children with cystic fibrosis and in heterozygous carriers. Clinica Chimica Acta 101(1), 17-24. DOI: 10.1016/0009-8981(80)90051-0.

Baum, J.A., Bogaert, T., Clinton, W., Heck, G.R., Feldmann, P. et al. (2007) Control of coleopteran insect pests through RNA interference. Nature Biotechnology 25(11), 1322-1326. DOI: 10.1038/nbt1359.

Bolognesi, R., Ramaseshadri, P., Anderson, J., Bachman, P., Clinton, W. et al. (2012) Characterizing the mechanism of action of double-stranded RNA activity against Western corn rootworm (Diabrotica virgifera virgifera LeConte). PLOS ONE 7(10), e47534. DOI: 10.1371/journal.pone.0047534.

Bonnet, E., He, Y., Billiau, K. and Van de Peer, Y. (2010) TAPIR, a web server for the prediction of plant microRNA targets, including target mimics. Bioinformatics 26(12), 1566-1568. DOI: 10.1093/ bioinformatics/btq233. 
Brennecke, J., Stark, A., Russell, R.B. and Cohen, S.M. (2005) Principles of microRNA-target recognition. PLoS Biology 3, e85-418. DOI: 10.1371/journal.pbio.0030085.

Brodersen, P. and Voinnet, O. (2006) The diversity of RNA silencing pathways in plants. Trends in Genetics 22(5), 268-280. DOI: 10.1016/j.tig.2006.03.003.

Brown, B.D., Gentner, B., Cantore, A., Colleoni, S., Amendola, M. et al. (2007) Endogenous microRNA can be broadly exploited to regulate transgene expression according to tissue, lineage and differentiation state. Nature Biotechnology 25(12), 1457-1467. DOI: 10.1038/nbt1372.

Casacuberta, J.M., Devos, Y., du Jardin, P., Ramon, M., Vaucheret, H. et al. (2015) Biotechnological uses of RNAi in plants: risk assessment considerations. Trends in Biotechnology 33(3), 145-147. DOI: 10.1016/j.tibtech.2014.12.003.

Chapman, K.D., Austin-Brown, S., Sparace, S.A., Kinney, A.J., Ripp, K.G. et al. (2001) Transgenic cotton plants with increased seed oleic acid content. Journal of the American Oil Chemists' Society 78(9), 941-947. DOI: 10.1007/s11746-001-0368-y.

Chau, B.L. and Lee, K.A.W. (2007) Function and anatomy of plant siRNA pools derived from hairpin transgenes. Plant Methods 3(1), 13. DOI: 10.1186/1746-4811-3-13.

Chen, X., Zen, K. and Zhang, C.-Y. (2013) Lack of detectable oral bioavailability of plant microRNA after feeding in mice. Nature Biotechnology 31(11), 967-969. DOI: 10.1038/nbt.2741.

Christensen, J., Litherland, K., Faller, T., van de Kerkhof, E., Natt, F. et al. (2013) Metabolism studies of unformulated internally $3 \mathrm{H}$-labeled short interfering RNAs in mice. Drug Metabolism and Disposition 41(6), 1211-1219. DOI: 10.1124/dmd.112.050666.

Codex (2003) Guideline for the conduct of food safety assessment of foods derived from recombinantDNA plants (CAC/GL 45-2003). Codex Alimentarius Commission, Joint FAO/WHO Food Standards Program. Food and Agriculture Organization, Rome, Italy.

Dai, X. and Zhao, P.X. (2011) psRNATarget: a plant small RNA target analysis server. Nucleic Acids Research 39(suppl. 2), W155-W159. DOI: 10.1093/nar/gkr319.

Della Vedova, C.B., Lorbiecke, R., Kirsch, H., Schulte, M.B., Scheets, K. et al. (2005) The dominant inhibitory chalcone synthase allele C2-Idf (inhibitor diffuse) from Zea mays (L.) acts via an endogenous RNA silencing mechanism. Genetics 170(4), 1989-2002. DOI: 10.1534/genetics.105.043406.

Devos, Y., Naegeli, H., Perry, J.N. and Waigmann, E. (2016) 90-day rodent feeding studies on whole GM food/feed: is the mandatory EU requirement for 90-day rodent feeding studies on whole GM food/ feed fit for purpose and consistent with animal welfare ethics? EMBO Reports 17, 942-945.

Dickinson, B., Zhang, Y., Petrick, J.S., Heck, G., Ivashuta, S. et al. (2013) Lack of detectable oral bioavailability of plant microRNA after feeding in mice. Nature Biotechnology 31(11), 965-967. DOI: 10.1038/ nbt.2737.

Dougherty, W.G., Lindbo, J.A., Smith, H.A., Parks, T.D., Swaney, S. (1994) RNA-mediated virus resistance in transgenic plants: exploitation of a cellular pathway possibly involved in RNA degradation. Molecular Plant-Microbe Interactions 7(5), 554-552. DOI: 10.1094/MPMI-7-0554.

Du, C., Chen, Y., Wang, K., Yang, Z., Zhao, C. et al. (2018) Strong co-suppression impedes an increase in polyunsaturated fatty acids in seeds overexpressing FAD2. Journal of Experimental Botany 70(3), 985-994. DOI: 10.1093/jxb/ery378.

Dykxhoorn, D.M., Novina, C.D. and Sharp, P.A. (2003) Killing the messenger: short RNAs that silence gene expression. Nature Reviews Molecular Cell Biology 4(6), 457-467. DOI: 10.1038/nrm1129.

EC (2013) Commission implementing regulation (EU) NO 503/2013 of 3 April 2013 on applications for authorisation of genetically modified food and feed in accordance with regulation (EC) No. 1829/2003 of the European Parliament and of the Council and amending Commission regulations (EC) NO $641 / 2004$ and (EC) NO 1981/2006. Official Journal of the European Union L157, 1-48.

EFSA GMO Panel (2006) Opinion of the scientific panel on genetically modified organisms related to the notification (reference C/SE/96/3501) for the placing on the market of genetically modified potato EH92-527-1 with altered starch composition, for cultivation and production of starch, under part C of Directive 2001/18/EC from BASF plant science. EFSA Journal 323, 1-20.

EFSA GMO Panel (2011) Guidance for risk assessment of food and feed from genetically modified plants. EFSA Journal 9(5), 2150. DOI: 10.2903/j.efsa.2011.2150.

EFSA GMO Panel (2013) Scientific opinion on application EFSA-GMO-NL2007-45 for the placing on the market of herbicide-tolerant, high-oleic acid, genetically modified soybean 305423 for food and fees uses, import and processing under regulation (EC) NO 1829/2003 from pioneer. EFSA Journal 11, 3499. 
EFSA GMO Panel (2017) Annex II of the minutes of the 118th GMO plenary meeting: internal note on the strategy and technical aspects for small RNA plant off-target bioinformatics studies. Available at: https://www.efsa.europa.eu/sites/default/files/event/171025-m.pdf (accessed 30 March 2020).

EFSA GMO Panel (2018) Scientific opinion on the assessment of genetically modified maize MON 87411 for food and feed uses, import and processing, under regulation (EC) NO 1829/2003 (application EFSA-GMO-NL-2015-124). EFSA Journal 16, 5310.

Fairbairn, D.J., Cavallaro, A.S., Bernard, M., Mahalinga-lyer, J., Graham, M.W. et al. (2007) Host-delivered RNAi: an effective strategy to silence genes in plant parasitic nematodes. Planta 226(6), 1525-1533. DOI: 10.1007/s00425-007-0588-x.

FDA (2019) Biotechnology notification file No. 000164: FAD2KO, high oleic acid soybean. Food and Drug Administration, Center for Veterinary Medicine, Rockville, Maryland. Available at: https://www.fda. gov/media/120660/download (accessed 30 March 2020).

Feinberg, E.H. and Hunter, C.P. (2003) Transport of dsRNA into cells by the transmembrane protein SID-1. Science 301(5639), 1545-1547. DOI: 10.1126/science.1087117.

Fire, A., Xu, S., Montgomery, M.K., Kostas, S.A., Driver, S.E. et al. (1998) Potent and specific genetic interference by double-stranded RNA in Caenorhabditis elegans. Nature 391(6669), 806-811. DOI: $10.1038 / 35888$.

Fishilevich, E., Vélez, A.M., Storer, N.P., Li, H., Bowling, A.J. et al. (2016) RNAi as a management tool for the western corn rootworm, Diabrotica virgifera virgifera. Pest Management Science 72(9), 16521663. DOI: $10.1002 / p s .4324$.

Flemr, M., Malik, R., Franke, V., Nejepinska, J., Sedlacek, R. et al. (2013) A retrotransposon-driven dicer isoform directs endogenous small interfering RNA production in mouse oocytes. Cell 155(4), 807816. DOI: 10.1016/j.cell.2013.10.001.

Frizzi, A. and Huang, S. (2010) Tapping RNA silencing pathways for plant biotechnology. Plant Biotechnology Journal 8(6), 655-677. DOI: 10.1111/j.1467-7652.2010.00505.x.

Gebert, L.F.R. and MacRae, I.J. (2019) Regulation of microRNA function in animals. Nature Reviews Molecular Cell Biology 20(1), 21-37. DOI: 10.1038/s41580-018-0045-7.

Ghildiyal, M., Seitz, H., Horwich, M.D., Li, C., Du, T. et al. (2008) Endogenous siRNAs derived from transposons and mRNAs in Drosophila somatic cells. Science 320(5879), 1077-1081. DOI: 10.1126/ science.1157396.

Gilmore, I.R., Fox, S.P., Hollins, A.J., Sohail, M. and Akhtar, S. (2004) The design and exogenous delivery of siRNA for post-transcriptional gene silencing. Journal of Drug Targeting 12(6), 315-340. DOI: $10.1080 / 10611860400006257$.

Gordon, K.H.J. and Waterhouse, P.M. (2007) RNAi for insect-proof plants. Nature Biotechnology 25(11), 1231-1232. DOI: 10.1038/nbt1107-1231.

Hannus, M., Beitzinger, M., Engelmann, J.C., Weickert, M.-T., Spang, R. et al. (2014) siPools: highly complex but accurately defined siRNA pools eliminate off-target effects. Nucleic Acids Research 42(12), 8049-8061. DOI: 10.1093/nar/gku480.

Haun, W., Coffman, A., Clasen, B.M., Demorest, Z.L., Lowy, A. et al. (2014) Improved soybean oil quality by targeted mutagenesis of the fatty acid desaturase 2 gene family. Plant Biotechnology Journal 12(7), 934-940. DOI: 10.1111/pbi.12201.

Heidel, J.D., Hu, S., Liu, X.F., Triche, T.J. and Davis, M.E. (2004) Lack of interferon response in animals to naked siRNAs. Nature Biotechnology 22(12), 1579-1582. DOI: 10.1038/nbt1038.

Heisel, S.E., Zhang, Y., Allen, E., Guo, L., Reynolds, T.L. et al. (2008) Characterization of unique small RNA populations from rice grain. PLOS ONE 3(8), e2871. DOI: 10.1371/journal.pone.0002871.

Huang, G., Allen, R., Davis, E.L., Baum, T.J. and Hussey, R.S. (2006) Engineering broad root-knot resistance in transgenic plants by RNAi silencing of a conserved and essential root-knot nematode parasitism gene. Proceedings of the National Academy of Sciences 103(39), 14302-14306. DOI: 10.1073/pnas.0604698103.

Huang, H., Davis, C. and Wang, T. (2018) Extensive degradation and low bioavailability of orally consumed corn miRNAs in mice. Nutrients 10(2), 215. DOI: 10.3390/nu10020215.

Hunter, C.P., Winston, W.M., Molodowitch, C., Feinberg, E.H., Shih, J. et al. (2006) Systemic RNAi in Caenorhabditis elegans. Cold Spring Harbor Symposia on Quantitative Biology 71, 95-100. DOI: 10.1101/sqb.2006.71.060.

Huvenne, H. and Smagghe, G. (2010) Mechanisms of dsRNA uptake in insects and potential of RNAi for pest control: a review. Journal of Insect Physiology 56(3), 227-235. DOI: 10.1016/j. jinsphys.2009.10.004. 
ILSI (2004) Nutritional and safety assessments of foods and feeds nutritionally improved through biotechnology: an executive summary. Comprehensive Reviews in Food Science and Food Safety 3, 35-104.

Ivashuta, S.I., Petrick, J.S., Heisel, S.E., Zhang, Y., Guo, L. et al. (2009) Endogenous small RNAs in grain: Semi-quantification and sequence homology to human and animal genes. Food and Chemical Toxicology 47(2), 353-360. DOI: 10.1016/j.fct.2008.11.025.

Jain, K. (2008) Stability and delivery of RNA via the gastrointestinal tract. Current Drug Delivery 5(1), 27-31. DOI: 10.2174/156720108783331023.

Jonas, D.A., Elmadfa, I., Engel, K.-H., Heller, K.J., Kozianowski, G. et al. (2001) Safety considerations of DNA in food. Annals of Nutrition and Metabolism 45(6), 235-254. DOI: 10.1159/000046734.

Jones-Rhoades, M.W., Bartel, D.P. and Bartel, B. (2006) MicroRNAs and their regulatory roles in plants. Annual Review of Plant Biology 57(1), 19-53. DOI: 10.1146/annurev.arplant.57.032905.105218.

Jose, A.M. and Hunter, C.P. (2007) Transport of sequence-specific RNA interference information between cells. Annual Review of Genetics 41(1), 305-330. DOI: 10.1146/annurev.genet.41.110306. 130216.

Judge, A. and MacLachlan, I. (2008) Overcoming the innate immune response to small interfering RNA. Human Gene Therapy 19(2), 111-124. DOI: 10.1089/hum.2007.179.

Kang, W., Bang-Berthelsen, C.H., Holm, A., Houben, A.J.S., Müller, A.H. et al. (2017) Survey of 800+ data sets from human tissue and body fluid reveals xenomRs are likely artifacts. RNA 23(4), 433-445. DOI: 10.1261/rna.059725.116.

Khatsenko, O., Morgan, R., Truong, L., York-Defalco, C., Sasmor, H. et al. (2000) Absorption of antisense oligonucleotides in rat intestine: effect of chemistry and length. Antisense and Nucleic Acid Drug Development 10(1), 35-44. DOI: 10.1089/oli.1.2000.10.35.

Kinney, A.J. and Knowlton, S. (1998) Designer oils: the high oleic acid soybean. In: Roller, S. and Harlander, S. (eds) Genetic Modification in the Food Industry: A Strategy for Food Quality Improvement. Boston, Massachusetts, Springer US, pp. 193-213.

Koch, A. and Kogel, K.-H. (2014) New wind in the sails: improving the agronomic value of crop plants through RNAi-mediated gene silencing. Plant Biotechnology Journal 12(7), 821-831. DOI: 10.1111/ pbi.12226.

Kusaba, M., Miyahara, K., lida, S., Fukuoka, H., Takano, T. et al. (2003) Low glutelin content1: A dominant mutation that suppresses the glutelin multigene family via RNA silencing in rice. The Plant Cell 15(6), 1455-1467. DOI: 10.1105/tpc.011452.

Lassek, E. and Montag, A. (1990) Nucleic acids components in carbohydrate-rich food. Zeitschrift für Lebensmittel-Untersuchung und -Forschung 190, 17-21.

Layzer, J.M., McCaffrey, A.P., Tanner, A.K., Huang, Z., Kay, M.A. (2004) In vivo activity of nuclease-resistant siRNAs. RNA 10(5), 766-771. DOI: 10.1261/rna.5239604.

Le, L., Mahler, V., Lorenz, Y., Scheurer, S., Biemelt, S. et al. (2006) Reduced allergenicity of tomato fruits harvested from Lyc e 1-silenced transgenic tomato plants. Journal of Allergy and Clinical Immunology 118(5), 1176-1183. DOI: 10.1016/j.jaci.2006.06.031.

Lemons, D., Maurya, M.R., Subramaniam, S. and Mercola, M. (2013) Developing microRNA screening as a functional genomics tool for disease research. Frontiers in Physiology 4, 223. DOI: 10.3389/ fphys.2013.00223.

Li, J., Yang, Z., Yu, B., Liu, J. and Chen, X. (2005) Methylation protects miRNAs and siRNAs from a 3 '-end uridylation activity in Arabidopsis. Current Biology 15(16), 1501-1507. DOI: 10.1016/j. cub.2005.07.029.

Liu, Q., Wang, F. and Axtell, M.J. (2014) Analysis of complementarity requirements for plant microRNA targeting using a Nicotiana benthamiana quantitative transient assay. The Plant Cell 26(2), 741-753. DOI: 10.1105/tpc.113.120972.

Liu, Y., Zhang, Y., Dong, P., An, R., Xue, C. et al. (2015) Digestion of nucleic acids starts in the stomach. Scientific Reports 5(1), 11936. DOI: 10.1038/srep11936.

Liu, S., da Cunha, A. P., Rezende, R. M., Cialic, R., Wei, Z. et al. (2016) The host shapes the gut microbiota via fecal microRNA. Cell Host \& Microbe 19(1), 32-43. DOI: 10.1016/j.chom.2015.12.005.

Loretz, B., Föger, F., Werle, M. and Bernkop-Schnürch, A. (2006) Oral gene delivery: strategies to improve stability of pDNA towards intestinal digestion. Journal of Drug Targeting 14(5), 311-319. DOI: 10.1080/10611860600823766.

Lukasik, A. and Zielenkiewicz, P. (2019) An overview of miRNA and miRNA target analysis tools. In: de Folter, S. (ed.) Plant MicroRNAs: Methods and Protocols. Springer, New York, New York, pp. 65-87. 
Ma, J.-B., Ye, K. and Patel, D.J. (2004) Structural basis for overhang-specific small interfering RNA recognition by the PAZ domain. Nature 429(6989), 318-322. DOI: 10.1038/nature02519.

Ma, Z., Li, J., He, F., Wilson, A., Pitt, B. et al. (2005) Cationic lipids enhance siRNA-mediated interferon response in mice. Biochemical and Biophysical Research Communications 330(3), 755-759. DOI: 10.1016/j.bbrc.2005.03.041.

Maeda, I., Kohara, Y., Yamamoto, M. and Sugimoto, A. (2001) Large-scale analysis of gene function in Caenorhabditis elegans by high-throughput RNAi. Current Biology 11(3), 171-176. DOI: 10.1016/ S0960-9822(01)00052-5.

Maida, Y. and Masutomi, K. (2011) RNA-dependent RNA polymerases in RNA silencing. Biological Chemistry 392(4), 299-304. DOI: 10.1515/bc.2011.035.

Manjunath, N. and Dykxhoorn, D.M. (2010) Advances in synthetic siRNA delivery. Discovery Medicine 9, 418-430.

Mao, Y.-B., Cai, W.-J., Wang, J.-W., Hong, G.-J., Tao, X.-Y. et al. (2007) Silencing a cotton bollworm P450 monooxygenase gene by plant-mediated RNAi impairs larval tolerance of gossypol. Nature Biotechnology 25(11), 1307-1313. DOI: 10.1038/nbt1352.

Mayoral, J.G., Hussain, M., Joubert, D.A., Iturbe-Ormaetxe, I., O'Neill, S.L. and Asgari, S. et al. (2014) Wolbachia small noncoding RNAs and their role in cross-kingdom communications. Proceedings of the National Academy of Sciences 111(52), 18721-18726. DOI: 10.1073/pnas.1420131112.

McEwan, D. L., Weisman, A. S. and Hunter, C. P. (2012) Uptake of extracellular double-stranded RNA by SID-2. Molecular Cell 47(5), 746-754. DOI: 10.1016/j.molcel.2012.07.014.

Meister, G., Landthaler, M., Patkaniowska, A., Dorsett, Y., Teng, G. et al. (2004) Human Argonaute2 mediates RNA cleavage targeted by miRNAs and siRNAs. Molecular Cell 15(2), 185-197. DOI: 10.1016/j. molcel.2004.07.007.

Meyer, P., Linn, F., Heidmann, I., Meyer, H., Niedenhof, I. et al. (1992) Endogenous and environmental factors influence $35 \mathrm{~S}$ promoter methylation of a maize A1 gene construct in transgenic Petunia and its colour phenotype. Molecular and General Genetics MGG 231(3), 345-352. DOI: 10.1007/ BF00292701.

Miller, S.C., Miyata, K., Brown, S.J. and Tomoyasu, Y. (2012) Dissecting systemic RNA interference in the red flour beetle Tribolium castaneum: parameters affecting the efficiency of RNAi. PLOS ONE 7(10), e47431. DOI: 10.1371/journal.pone.0047431.

Mittelbrunn, M. and Sánchez-Madrid, F. (2012) Intercellular communication: diverse structures for exchange of genetic information. Nature Reviews Molecular Cell Biology 13(5), 328-335. DOI: 10.1038/ nrm3335.

Méndez-Acevedo, K.M., Valdes, V.J., Asanov, A. and Vaca, L. (2017) A novel family of mammalian transmembrane proteins involved in cholesterol transport. Scientific Reports 7(1), 7450. DOI: 10.1038/ s41598-017-07077-z.

Nejepinska, J., Malik, R., Filkowski, J., Flemr, M., Filipowicz, W. et al. (2012) dsRNA expression in the mouse elicits RNAi in oocytes and low adenosine deamination in somatic cells. Nucleic Acids Research 40(1), 399-413. DOI: 10.1093/nar/gkr702.

Newmark, P.A., Reddien, P.W., Cebria, F. and Sanchez Alvarado, A. (2003) Ingestion of bacterially expressed double-stranded RNA inhibits gene expression in planarians. Proceedings of the National Academy of Sciences 100(Supplement 1), 11861-11865. DOI: 10.1073/pnas.1834205100.

Nicklin, P.L., Bayley, D., Giddings, J., Craig, S.J., Cummins, L.L. et al. (1998) Pulmonary bioavailability of a phosphorothioate oligonucleotide (CGP 64128A): comparison with other delivery routes. Pharmaceutical Research 15(4), 583-591. DOI: 10.1023/A:1011934011690.

OECD (2002) Consensus document on compositional considerations for new varieties of maize (Zea mays): key food and feed nutrients, anti-nutrients and secondary plant metabolites. Organisation for Economic Co-operation and Development, Paris. Available at: http://www.oecd.org/chemicalsafety/ biotrack/46815196.pdf (accessed 30 March 2020).

Ogita, S., Uefuji, H., Yamaguchi, Y., Koizumi, N. and Sano, H. (2003) RNA interference: producing decaffeinated coffee plants. Nature 423, 823.

Okuzaki, A., Ogawa, T., Koizuka, C., Kaneko, K., Inaba, M. et al. (2018) CRISPR/Cas9-mediated genome editing of the fatty acid desaturase 2 gene in Brassica napus. Plant Physiology and Biochemistry 131, 63-69. DOI: 10.1016/j.plaphy.2018.04.025.

O'Neill, M.J., Bourre, L., Melgar, S. and O'Driscoll, C.M. (2011) Intestinal delivery of non-viral gene therapeutics: physiological barriers and preclinical models. Drug Discovery Today 16(5-6), 203-218. DOI: 10.1016/j.drudis.2011.01.003. 
Pačes, J., Nič, M., Novotný, T. and Svoboda, P. (2017) Literature review of baseline information to support the risk assessment of RNAi-based GM plants. EFSA Supporting Publication 14(6), EN-1246. European Food Safety Authority, Parma, Italy, p. 314.

Park, N.J., Li, Y., Yu, T., Brinkman, B.M.N. and Wong, D.T. (2006) Characterization of RNA in saliva. Clinical Chemistry 52(6), 988-994. DOI: 10.1373/clinchem.2005.063206.

Pasquinelli, A.E. (2012) MicroRNAs and their targets: recognition, regulation and an emerging reciprocal relationship. Nature Reviews Genetics 13(4), 271-282. DOI: 10.1038/nrg3162.

Petrick, J.S., Brower-Toland, B., Jackson, A.L. and Kier, L.D. (2013) Safety assessment of food and feed from biotechnology-derived crops employing RNA-mediated gene regulation to achieve desired traits: a scientific review. Regulatory Toxicology and Pharmacology 66(2), 167-176. DOI: 10.1016/j. yrtph.2013.03.008.

Petrick, J.S., Moore, W.M., Heydens, W.F., Koch, M.S., Sherman, J.H. et al. (2015) A 28-day oral toxicity evaluation of small interfering RNAs and a long double-stranded RNA targeting vacuolar ATPase in mice. Regulatory Toxicology and Pharmacology 71(1), 8-23. DOI: 10.1016/j.yrtph.2014.10.016.

Petrick, J.S., Frierdich, G.E., Carleton, S.M., Kessenich, C.R., Silvanovich, A. et al. (2016) Corn rootworm-active DvSnf7: repeat dose oral toxicology assessment in support of human and mammalian safety. Regulatory Toxicology and Pharmacology 81, 57-68. DOI: 10.1016/j. yrtph.2016.07.009.

Pinzón, N., Li, B., Martinez, L., Sergeeva, A., Presumey, J. et al. (2017) MicroRNA target prediction programs predict many false positives. Genome Research 27(2), 234-245. DOI: 10.1101/gr.205146.116.

Ramon, M., Devos, Y., Lanzoni, A., Liu, Y., Gomes, A. et al. (2014) RNAi-based GM plants: food for thought for risk assessors. Plant Biotechnology Journal 12(9), 1271-1273. DOI: 10.1111/pbi.12305.

Redenbaugh, K., Hiatt, B., Martineau, B., Kramer, M. and Sheehy, R. (1992) Safety Assessment of Genetically Engineered Fruits and Vegetables: a Case Study of the Flavr Savr Tomato. CRC Press, Boca Raton, Florida, p. 288.

Regina, A., Bird, A., Topping, D., Bowden, S., Freeman, J. et al. (2006) High-amylose wheat generated by RNA interference improves indices of large-bowel health in rats. Proceedings of the National Academy of Sciences 103(10), 3546-3551. DOI: 10.1073/pnas.0510737103.

Ren, G., Xie, M., Zhang, S., Vinovskis, C., Chen, X. et al. (2014) Methylation protects microRNAs from an AGO1-associated activity that uridylates 5 ' RNA fragments generated by AGO1 cleavage. Proceedings of the National Academy of Sciences 111(17), 6365-6370. DOI: 10.1073/pnas.1405083111.

Rhoades, M.W., Reinhart, B.J., Lim, L.P., Burge, C.B., Bartel, B. et al. (2002) Prediction of plant micro RNA targets. Cell 110(4), 513-520. DOI: 10.1016/S0092-8674(02)00863-2.

Robbins, M., Judge, A. and MacLachlan, I. (2009) siRNA and innate immunity. Oligonucleotides 19(2), 89-102. DOI: 10.1089/oli.2009.0180.

Schuppert, G.F., Tang, S., Slabaugh, M.B. and Knapp, S.J. (2006) The sunflower high-oleic mutant ol carries variable tandem repeats of FAD2-1, a seed-specific oleoyl-phosphatidyl choline desaturase. Molecular Breeding 17(3), 241-256. DOI: 10.1007/s11032-005-5680-y.

Senthil-Kumar, M. and Mysore, K.S. (2011) Caveat of RNAi in plants: the off-target effect. Methods in Molecular Biology 744, 13-25.

Sherman, J.H., Munyikwa, T., Chan, S.Y., Petrick, J.S., Witwer, K.W. et al. (2015) RNAi technologies in agricultural biotechnology: the toxicology forum 40th annual summer meeting. Regulatory Toxicology and Pharmacology 73(2), 671-680. DOI: 10.1016/j.yrtph.2015.09.001.

Sioud, M. (2005) On the delivery of small interfering RNAs into mammalian cells. Expert Opinion on Drug Delivery 2(4), 639-651. DOI: 10.1517/17425247.2.4.639.

Sivaraman, I., Arumugam, N., Sodhi, Y.S., Gupta, V., Mukhopadhyay, A. et al. (2004) Development of high oleic and low linoleic acid transgenics in a zero erucic acid Brassica juncea L. (Indian mustard) line by antisense suppression of the fad2 gene. Molecular Breeding 13(4), 365-375. DOI: 10.1023/B:MOLB.0000034092.47934.d6.

Snow, J.W., Hale, A.E., Isaacs, S.K., Baggish, A.L. and Chan, S.Y. (2013) Ineffective delivery of dietderived microRNAs to recipient animal organisms. RNA Biology 10(7), 1107-1116. DOI: 10.4161/ rna.24909.

Stein, P., Svoboda, P., Anger, M. and Schultz, R.M. (2003) RNAi: mammalian oocytes do it without RNAdependent RNA polymerase. RNA 9(2), 187-192. DOI: 10.1261/rna.2860603.

Tabara, H., Grishok, A. and Mello, C.C. (1998) RNAi in C. elegans: soaking in the genome sequence. Science 282(5388), 430-431. DOI: 10.1126/science.282.5388.430. 
Terenius, O., Papanicolaou, A., Garbutt, J.S., Eleftherianos, I., Huvenne, H. et al. (2011) RNA interference in Lepidoptera: an overview of successful and unsuccessful studies and implications for experimental design. Journal of Insect Physiology 57(2), 231-245. DOI: 10.1016/j.jinsphys.2010.11.006.

Tian, Y., Simanshu, D.K., Ma, J.-B. and Patel, D.J. (2011) Structural basis for piRNA 2'-O-methylated 3'end recognition by Piwi PAZ (Piwi/Argonaute/Zwille) domains. Proceedings of the National Academy of Sciences 108(3), 903-910. DOI: 10.1073/pnas.1017762108.

Timmons, L., Court, D.L. and Fire, A. (2001) Ingestion of bacterially expressed dsRNAs can produce specific and potent genetic interference in Caenorhabditis elegans. Gene 263(1-2), 103-112. DOI: 10.1016/S0378-1119(00)00579-5.

Tomari, Y. and Zamore, P.D. (2005) Perspective: machines for RNAi. Genes \& Development 19(5), 517529. DOI: $10.1101 /$ gad.1284105.

Tosar, J.P., Rovira, C., Naya, H. and Cayota, A. (2014) Mining of public sequencing databases supports a non-dietary origin for putative foreign miRNAs: underestimated effects of contamination in NGS. RNA 20(6), 754-757. DOI: 10.1261/rna.044263.114.

Tuteja, J.H., Clough, S.J., Chan, W.-C. and Vodkin, L.O. (2004) Tissue-specific gene silencing mediated by a naturally occurring chalcone synthase gene cluster in Glycine max. The Plant Cell 16(4), 819-835. DOI: 10.1105/tpc.021352.

Vaishnaw, A.K., Gollob, J., Gamba-Vitalo, C., Hutabarat, R., Sah, D. et al. (2010) A status report on RNAi therapeutics. Silence 1, 14. DOI: 10.1186/1758-907X-1-14.

van der Hoeven, C., Dietz, A. and Landsmann, J. (1994) Variability of organ-specific gene expression in transgenic tobacco plants. Transgenic Research 3, 159-166. DOI: 10.1007/BF01973983.

Vazquez, F. (2006) Arabidopsis endogenous small RNAs: highways and byways. Trends in Plant Science 11(9), 460-468. DOI: 10.1016/j.tplants.2006.07.006.

Wagner, E.G.H. and Romby, P. (2015) Small RNAs in bacteria and archaea: who they are, what they do, and how they do it. Advances in Genetics 90, 133-208. DOI: 10.1016/bs.adgen.2015.05.001.

Waltz, E. (2015) Nonbrowning GM apple cleared for market. Nature biotechnology 33(4), 326-327. DOI: 10.1038/nbt0415-326c.

Winston, W.M., Molodowitch, C. and Hunter, C.P. (2002) Systemic RNAi in C. elegans requires the putative transmembrane protein SID-1. Science 295(5564), 2456-2459. DOI: 10.1126/ science.1068836.

Winston, W.M., Sutherlin, M., Wright, A.J., Feinberg, E.H. and Hunter, C.P. (2007) Caenorhabditis elegans SID-2 is required for environmental RNA interference. Proceedings of the National Academy of Sciences 104(25), 10565-10570. DOI: 10.1073/pnas.0611282104.

Witwer, K.W. (2018) Alternative miRNAs? Human sequences misidentified as plant miRNAs in plant studies and in human plasma. F1000Research 7, 244. DOI: 10.12688/f1000research.14060.1.

Witwer, K.W., McAlexander, M.A., Queen, S.E. and Adams, R.J. (2013) Real-Time quantitative PCR and droplet digital PCR for plant miRNAs in mammalian blood provide little evidence for general uptake of dietary miRNAs: limited evidence for general uptake of dietary plant xenomiRs. RNA Biology 10(7), 1080-1086. DOI: 10.4161/rna.25246.

Wood, C.C., Okada, S., Taylor, M.C., Menon, A., Mathew, A. et al. (2018) Seed-specific RNAi in safflower generates a superhigh oleic oil with extended oxidative stability. Plant Biotechnology Journal 16(10), 1788-1796. DOI: 10.1111/pbi.12915.

Yadav, B.C., Veluthambi, K. and Subramaniam, K. (2006) Host-generated double stranded RNA induces RNAi in plant-parasitic nematodes and protects the host from infection. Molecular and Biochemical Parasitology 148(2), 219-222. DOI: 10.1016/j.molbiopara.2006.03.013.

Yang, J., Farmer, L.M., Agyekum, A.A.A. and Hirschi, K.D. (2015a) Detection of dietary plant-based small RNAs in animals. Cell Research 25(4), 517-520. DOI: 10.1038/cr.2015.26.

Yang, J., Farmer, L.M., Agyekum, A.A.A., Elbaz-Younes, I. and Hirschi, K.D. (2015b) Detection of an abundant plant-based small RNA in healthy consumers. PLoS ONE10(9), e0137516. DOI: 10.1371/journal.pone.0137516.

Yang, J., Hotz, T., Broadnax, L., Yarmarkovich, M., Elbaz-Younes, I. et al. (2016) Anomalous uptake and circulatory characteristics of the plant-based small RNA MIR2911. Scientific Reports 6, 26834. DOI: 10.1038/srep26834.

Yang, J., Kongchan, N., Primo Planta, C., Neilson, J.R. and Hirschi, K.D. (2017) The atypical genesis and bioavailability of the plant-based small RNA MIR2911: bulking up while breaking down. Molecular Nutrition \& Food Research 61(9), 1600974. DOI: 10.1002/mnfr.201600974. 
Yang, J., Elbaz-Younes, I., Primo, C., Murungi, D. and Hirschi, K.D. (2018) Intestinal permeability, digestive stability and oral bioavailability of dietary small RNAs. Scientific Reports 8(1), 10253. DOI: 10.1038/ s41598-018-28207-1.

Yu, B., Yang, Z., Li, J., Minakhina, S., Yang, M. et al. (2005) Methylation as a crucial step in plant micro RNA biogenesis. Science 307(5711), 932-935. DOI: 10.1126/science.1107130.

Yuan, T., Huang, X., Woodcock, M., Du, M., Dittmar, R. et al. (2016) Plasma extracellular RNA profiles in healthy and cancer patients. Scientific Reports 6, 19413. DOI: 10.1038/srep19413.

Zhang, Y., Wiggins, B.E., Lawrence, C., Petrick, J., Ivashuta, S. et al. (2012a) Analysis of plant-derived miRNAs in animal small RNA datasets. BMC Genomics 13, 381. DOI: 10.1186/1471-2164-13-381.

Zhang, L., Hou, D., Chen, X., Li, D., Zhu, L. et al. (2012b) Exogenous plant MIR 168a specifically targets mammalian LDLRAP1: evidence of cross-kingdom regulation by microRNA. Cell Research 22(1), 107-126. DOI: 10.1038/cr.2011.158.

Zhang, J., Khan, S.A., Hasse, C., Ruf, S., Heckel, D.G. et al. (2015) Full crop protection from an insect pest by expression of long double-stranded RNAs in plastids. Science 347(6225), 991-994. DOI: 10.1126/science.1261680.

Zhang, J., Khan, S.A., Heckel, D.G. and Bock, R. (2017) Next-generation insect-resistant plants: RNAi-mediated crop protection. Trends in Biotechnology 35(9), 871-882. DOI: 10.1016/j. tibtech.2017.04.009.

Zhou, X.H., Dong, Y., Xiao, X., Wang, Y., Xu, Y. et al. (2011) A 90-day toxicology study of high-amylose transgenic rice grain in Sprague-Dawley rats. Food and Chemical Toxicology 49(12), 3112-3118. DOI: 10.1016/j.fct.2011.09.024.

Zhou, X.H., Dong, Y., Wang, Y., Xiao, X., Xu, Y. et al. (2012) A three generation study with high-lysine transgenic rice grain in Sprague-Dawley rats. Food and Chemical Toxicology 50(6), 1902-1910. DOI: 10.1016/j.fct.2012.04.001. 